\title{
7
}

\section{Against the Tide: Transnational Solidarity in Brexit Britain}

\section{Simone Baglioni, Olga Biosca, and Tom Montgomery}

\section{Introduction}

The austerity that has come to shape the policies and politics of contemporary Britain generates challenges for all forms of solidarity. The needs of vulnerable groups increase while the resources of organisations engaged in solidarity come under pressure. The context in which our interviews were conducted is one where communities are still dealing with the impact of austerity policies (O'Hara 2015) that have followed a legacy of decades of privatisation resulting in a rolling back of the state (Peck and Tickell 2002). Thus, the transnational solidarity organisations (TSOs),

S. Baglioni $(\bowtie)$

Department of Economics and Management, University of Parma,

Parma, Italy

e-mail: simone.baglioni@unipr.it

O. Biosca • T. Montgomery

Yunus Centre for Social Business and Health, Glasgow Caledonian University, Glasgow, UK

e-mail: olga.biosca@gcu.ac.uk; thomas.montgomery@gcu.ac.uk

(C) The Author(s) 2021

C. Lahusen et al. (eds.), Transnational Solidarity in Times of Crises, Palgrave Studies in

European Political Sociology, https://doi.org/10.1007/978-3-030-49659-3_7 
which form the focus of our study, are not simply performing, in some sectors of society, a complementary role to the welfare state but in fact playing a critical role in meeting the basic needs of vulnerable groups. Indeed our findings of the contemporary context reveal a tale of 'two Britains'. On the one hand is a Britain of top-down policies and discourses which are anti-solidarity, reactionary and re-activate decades-old discourses of dependency (Wiggan 2012) and deservingness (Stewart and Mulvey 2014). On the other hand is a Britain of grassroots solidarity, (self-)organised from the bottom up, often with the partnership and support of local government, a layer of governance that has itself been on the front line of austerity measures with local authorities in England on course for a $75 \%$ cut to their total funding from central government by 2020 (Smulian 2017). It is within this context our study took place, where we chose to focus on solidarity with vulnerable groups whose needs increased while services were being rolled back and policies became ever more hostile and punitive. Therefore, the focal point of our research has been those TSOs working with three vulnerable groups: (1) migrants, refugees and asylum seekers; (2) disabled people; and (3) the unemployed.

Our interviews with TSOs in the field of migration in the UK took place against the aftermath of the referendum on European Union (EU) membership where the issue of immigration was at the very forefront of the 'leave campaign' and was at the centre of concerns following media reports of increased levels of xenophobia (Ferguson 2016). Nevertheless, immigration has been a consistent source of contestation with senior politicians labelling Britain a 'soft touch' (Prime Minister's Office 2013) for benefit tourism amidst a context where the media have played an active role in the fomenting of xenophobia (Greenslade 2005). In this landscape, the UK has been among those countries accepting the lowest number of Syrian refugees.

Similarly, in the field of disability, UK Government policy has become an area of political contestation given the extent to which cuts to the welfare state have had a significant impact on the living conditions of disabled people. This manifested itself in welfare reforms including the Work Capability Assessment, introduced by the Labour Government in 2008 (Bambra and Smith 2010) and expanded by the Coalition Government in 2010 (Baumberg et al. 2015), which led to narrower 
entitlements to benefits, with disabled people who previously were assessed as unable to work being redefined as fit for work (Wright 2012). Thus TSOs in the field of disability in the UK find themselves operating in a context which a United Nations inquiry has condemned for the 'systematic violations of the rights of persons with disabilities' (United Nations 2016: 20).

Moreover, the field of unemployment has been at the forefront of concerns for policymakers in the UK since the onset of the global financial crisis and those concerns have never seemed to diminish. Indeed, following the result of the EU referendum in June 2016, one of the key concerns has been the potential job losses that may occur as a consequence. Workers in the UK, whether in the private or public sector, are now navigating ever more challenging labour markets. These are increasingly characterised by non-standard forms of employment such as 'zero-hour contracts' (Pennycook et al. 2013) in 'low pay, no pay cycles' (Shildrick et al. 2012) complemented by a welfare system characterised by sanctions and compulsion (Watts and Fitzpatrick 2018).

It is against this backdrop that we undertook our study of TSOs across the three fields. Our study was guided by a central research question: how do transnational solidarity organisations meet the needs of vulnerable groups in times of crisis and austerity? To answer this question, through the analysis of our findings from interviews with TSOs, we structure the chapter as follows: (1) we set out our research design; (2) we explore the interactions, both positive and negative, that our interviewees in TSOs have with policymakers; (3) we investigate the impact of austerity across organisations participating in this study; (4) we elaborate on the mission, innovative activities and key individuals of the TSOs we interviewed and the groups within UK society whom their solidaristic efforts focus on; (5) we examine the cooperation between TSOs at different scales (transnational, national and local). Finally, we outline our conclusions on the key findings and their implications for future research on transnational solidarity across the three vulnerable groups which form the focus of this study. 


\section{Research Design}

The focus of this chapter is an analysis of interviews conducted with organisations engaged in solidarity with different vulnerable groups across the UK. From the larger random sample of 300 TSOs, 30 were purposively sampled following a maximum variation strategy in the context of Work Package 2 of the TransSOL cross-national project. ${ }^{1}$ Ten TSOs were selected across each of the fields of migration, unemployment and disability, and we sampled TSOs involved in service delivery as well as those more activist-led and oriented towards policy change. Geographical diversity was achieved by sampling across the constituent nations of the UK, from large urban conurbations such as Glasgow, Manchester and London to rural areas such as mid-Wales and coastal communities in the south of England. Our interviewees in the TSOs were also diverse (e.g. age, gender, ethnicity and disabilities) (TransSOL 2016).

In the field of migration, participant TSOs represented a mix of formal and informal organisations. Some were part of a broader network across the UK, others were a network to bring together a variety of actors supporting migrants and refugees, and another group was focused on the needs of specific migrant communities. TSOs were also geographically spread throughout the UK and therefore provide us with a solid overview of the spatial context within which these organisations were meeting the needs of those settling or seeking asylum in the UK. In the field of disability, we found that although most of the disability TSOs had a headquarters with their own premises, very often interviewees declared themselves to be working remotely (a third of the interviews were conducted with people working outside of the organisation's premises) which reveals to some extent the ability of these organisations to work as reticular connectors of skills and capacities dislocated across diverse geographical settings.

\footnotetext{
${ }^{1}$ This project has received funding from the European Union's Horizon 2020 research and innovation programme under grant agreement No. 649435. For more information on sampling, see the Introduction to this volume and https://blogs.uni-siegen.de/transsol/files/2016/12/IntegratedReport-on-Reflective-Forms-of-Transnational-Solidarity.pdf
} 
Our interviews were conducted face to face or by telephone and were undertaken between September and October 2016. The interviews were transcribed and analysed to elicit key themes that were then organised to produce a coherent reflection of how TSOs were meeting the needs of specific vulnerable groups in times of crisis in contemporary Britain. We now turn to our findings from the interviews and the conclusions we can draw, beginning with the interactions between TSOs and policymaking.

\section{Interactions with Policymakers and the Impact of Austerity}

For some, though certainly not all the TSOs we interviewed, we uncovered a somewhat nuanced relationship with policymaking. On the one hand, there was contestation with dominant policy discourses emanating from central government but, on the other hand, there were partnerships between TSOs and those agencies or authorities that were also involved in meeting the needs of the vulnerable groups.

For example, a number of interviewees from migration TSOs described their organisations as having relatively good relationships with their respective local authorities. For example, one interviewee, a manager of a refugee project located on the south coast of England, described the partnership developed between his organisation and the city council as 'very positive' and that the council had adopted a welcoming attitude towards the arrival of new migrants, whilst placing this in contrast to what he described as an unwillingness of UK Governments to discuss and promote the positive aspects of migration, a conclusion mirrored in existing research (Statham and Geddes 2006). Moreover, although other interviewees would also describe their relationship with city councils as close and collaborative, this did not appear to be extended to the UK Government level where there was a consistent degree of criticism.

Some interviewees in the migration field were highly critical of the UK Government in their handling of the refugee crisis as well as the legal frameworks relating to migration more generally, with one interviewee suggesting that the work of her organisation to assist women migrants 
was simply not reflected in the actions of the UK Government which she insisted had its 'own agenda'. This mirrored the conclusion reached by another of our interviewees who asserted that:

Every Immigration Act has made the situation worse for asylum seekers and refugees. That is a submission to the populist anti-immigration agenda and has made things worse for anyone seeking protection in the UK. (Migr4 10/2016)

The same interviewee also articulated his belief that the legislative framework is intended to prevent the societal inclusion of asylum-seekers/ refugees with the purpose of managing their expectations. There was a shared perception that the current legal framework for migration lacked empathy towards migrants. In words of another interviewee from a TSO based in the south-east of England:

It's hard to be made less welcome; it's not a nice thing being a refugee in the UK and if you can't find a job, you go to Jobcentre plus and they really don't respect refugees...there is no staff training, people often report that it's a very unfriendly service. (Migr8 10/2016)

This hostile environment emanating from top-down central government being navigated by TSOs involved in organising solidarity with migrants and refugees was not unique, as our interviews with other TSOs revealed with many reporting similar experiences. One field where this was apparent was that of disability.

There was a consensus among the interviewees from TSOs supporting disabled people that the economic crisis and the austerity policies implemented by the UK Government have had a negative impact on disabled people and on the sector as a whole. This impact translated into a higher number of people suffering from mental distress due to increased financial and economic pressures, and a higher number of people who cannot afford to pay for certain health/care-related services that they require. With the public sector provision of such services itself being cut as a consequence of the crisis, disabled people could only access such services by paying for them. As one interviewee pointed out: 
with austerity policies, even access to statutory services has become more difficult. (Disab1 10/2016)

Moreover, austerity policies have been implemented through the reassessment of benefits entitlement, as well as a reshaping of benefits' claiming procedures (Patrick 2014). As a consequence, a significant portion of disabled people entitled to receive benefits either have lost this entitlement or have had difficulties in completing the claim procedure (some TSOs actively provide support to help disabled people 'navigate through the procedure' in order to avoid losing their benefits). These efforts often took place against a backdrop of stigmatisation where policy and media discourses depicting claimants of disability benefits as workshy and scroungers (Garthwaite 2011). Although some TSOs reported being advisors to relevant policymaking bodies, all referred to the difficulty experienced by the sector to enter policy discussions and to be recognised as competent and legitimate policy actors. Moreover, rather than being considered professional providers of high-quality services, TSOs claimed that they were often considered by policymakers as being amateurish, given that they are the 'voluntary' sector. As one interviewee elaborated:

We are considered 'free and cheap' as we are part of the 'voluntary sector', but they [policymakers] do not consider that training volunteers, running services and a charity organisation has costs. For example, we don't accept a volunteer no matter her/his background; we recruit volunteers only through a specific application procedure in which we value competences and skills. (Disab2 10/2016)

TSOs are proud of the capacity they deploy and are therefore seeking to be acknowledged properly for the role they play. Furthermore, TSOs in our sample claimed that even if their views were to be incorporated into policies, the lives of disabled people would not improve due to failures in the capacity of policy implementation currently experienced at the local level. Local authorities have been at the forefront of cuts and therefore cannot implement policies as they should. One of the interviewees stated that although the UK has well-meaning legislation, such as 
the Equality Act 2010 or the Care Act 2014, the potential of this legislation remains largely untapped as their proper implementation would require resources_-economic and human-which are not being made available. The TSOs we spoke to expressed regret that there was no serious challenge brought against the UK Government on their failure to fully implement this legislation. Challenging the government directly was, however, a more frequent occurrence with other TSOs, such as those in the field of unemployment.

Each of the TSOs in the field of unemployment we spoke to had some form of interaction with policymakers; however, this varied from quite formalised links to those who would engage on a more infrequent and informal basis. There was also a broad spectrum in terms of the types of relationships which existed, some in partnership and others, more antagonistic. Those interviewees from trade unions explained that they did in some cases have very good relationships with some policymakers, especially with those sympathetic with the trade union movement and actual trade union members. However, trade union interviewees perceived that they were locked in a confrontation with the UK Government over the introduction of new legislation, which some of the trade unions described as a political attack on worker representation, namely the Trade Union Act. This legislation had implications on issues such as turnout thresholds for strike ballots to financial consequences for trade unions (see Darlington and Dobson 2015). One official made it clear that she felt the Trade Union Act was a deliberate political attempt being made by the Conservative Government in the UK to undermine the trade union movement and prevent workers from being properly represented. This view was echoed by other trade union representatives we interviewed.

Our interviews also revealed how the economic context is affecting those TSOs geared towards supporting those seeking to re-enter the labour market. One interviewee, a director of a social enterprise, explained that not only the impact of the crisis meant a hardening of attitudes towards those who were unemployed, but also despite having no financial resources to do so, his organisation was frequently offering support to those who would previously have been supported by government agencies. The interviewee provided examples of some of the deep cuts to local authority services in his area including one situation, which had occurred 
the day before our interview, where a teenage girl presented herself at their drop-in centre having been referred there by social services. The interviewee recalled his conversation with social services:

We phoned up social services asking for a care plan, an assessment of where this girl's needs were and they said 'we can't deal with her now, our adult team is no longer running...she's now sixteen, we can't help her, our budget stops at sixteen'... That's not helping anybody. (Unemp5 09/2016)

Nevertheless, despite his organisation having to substitute for services no longer offered by the local authority, he was clear in his support for those working within the local public sector, highlighting the cuts that these agencies were coping with:

We have very good relations with social services; it's not their fault. (Unemp5 09/2016)

The understanding demonstrated by this interviewee towards the challenges faced by local government services that have been cut significantly due to austerity policies may not only stem from the working relationship his organisation had fostered with the local authority, but also stem from an empathy built on a shared experience of the difficulties in meeting often complex needs in a context of a shrinking pool of resources, an experience that a number of other TSOs could also relate.

What therefore becomes clear from our findings is that among the TSOs we interviewed, regardless of the field in which they were operating, there was a relationship with policymaking and policymakers that was far more nuanced than simply one of clear partnership or antagonism. Instead, although most TSOs were openly critical of the discourses and policy agenda stemming from the UK Government, many were also engaged in formal and informal partnerships with individual policymakers and public sector agencies. What perhaps united these actors was a common experience of trying to meet the growing needs of vulnerable groups while their organisations were navigating budget cuts that were hindering their ability to do so. 


\section{The Impact of Crisis and Austerity at the Grassroots Level}

During the course of our interviews, it became clear that both crises (the economic crisis and the so-called refugee crisis) have had a clear impact on the TSOs across different fields in the UK. Indeed, as some interviewees from migration TSOs explained, it was the issue of the potential influx of refugees which had acted as the main catalyst for their group to be founded, with one interviewee explaining that, in contrast to the UK media portraying a hostile environment for refugees, their group was keen to bring together the community to welcome refugees and to offer them practical support. This view was echoed by other interviewees operating in the field of migration who believed that there was a reality on the ground that was more welcoming, generous and supportive of refugees than the UK media portrayed. Nevertheless, other interviewees warned that they had detected a hardening of attitudes towards refugees in the UK, with one respondent, a coordinator of a refugee group in the north of England, expressing the belief (shared by another interviewee in the south-east of England) that the cuts to welfare spending, as well as how these cuts have been communicated via the media, have negatively impacted on attitudes towards refugees in the UK. Therefore, despite variations in perceptions across our interviewees, there was a consistent message expressed that the UK Government had done little in practical terms to assist refugees in the midst of that crisis.

Another dimension of crisis which emerged during our interviews was that the economic crisis was having an impact on the TSOs themselves, as well as on the people who formed the focus of their solidarity efforts. Overall, there was an awareness of an increasingly competitive environment for funding, with one interviewee from a migration TSO arguing that many third-sector organisations need to be perceived as 'innovative' now just to exist, perhaps underlining the conclusion reached by Osborne et al. (2008) that the focus on innovation in this sector may be a distraction from the more substantive contribution that can be made by these organisations. The concerns regarding funding were echoed by another 
practitioner in the migration field who believed that the decrease in funding opportunities reduced possibilities to work in partnership with other TSOs, particularly those at the transnational level. One interviewee outlined the nature of the challenge facing their organisation:

After the crisis, we feel more uncomfortable. It looks like the UK has lost direction and there are so many uncertainties that it is very difficult to forecast or plan our activities. It also makes it more difficult to apply for funding. (Migr5 10/2016)

In terms of the consequences of the crisis for the disability charity sector, there has been an obvious reduction in income available from donations or public procurement. According to our interviewees, the latter has become much more competitive (an interviewee speaking for a charity based in southern England explained that before the crisis, her organisation had a $60 \%$ success rate on bids to run services in the UK, whereas now its success rate amounts to $5 \%$ success, despite employing the same professionals to formulate bids). More competition, however, does not necessarily equate to better services: in fact, our interviews reveal that these disability charities are now competing to deliver services at lower prices than before, and even when an organisation wins a procurement contract, the implementation of the contract may be extremely challenging given that the public sector expects charities to do more work with fewer resources. Other salient consequences of the crisis are that service provision by the public sector is focused on those services which are considered mainstream in terms of addressing the needs of the wider population, and therefore services that are perceived to address a smaller pool of patients, although being essential to their well-being, are interrupted or considered 'niche' and, as such, too expensive.

A consistent theme across each of the unemployment TSOs we interviewed was that the financial crisis and the austerity measures which followed had a clear impact on members and service users. One trade union official whose membership were mainly workers in the private sector described the economic crisis as having a major impact on members leading to numerous redundancies. The same official added that the period 
following the crisis had actually reshaped the membership of the trade union which had in the past been predominantly male, but was now evenly split between male and female workers. Another trade union official explained that the crisis had led to pay freezes and changes for the public sector workers he represented. Moreover, he added that for many of the young workers now in the sector, poorer working conditions (for instance, longer working hours and changes to pensions) had become normalised and most of the young people were simply grateful to have a job with some level of security. Moreover, a number of interviewees engaged in the field of unemployment indicated that the crisis had financial implications for their organisation, with one respondent from a charity explaining that the situation had led to a financial crisis within her organisation which was already stretched to capacity. Other interviewees working with the same vulnerable group also made reference to the much more difficult funding environment that they found themselves in, with one interviewee from a social enterprise based in Glasgow explaining that the funding cycle had contracted from three years to one year and that she was concerned about the impact on their member organisations. At the individual level, one trade union official explained that the cost of living puts financial pressure on members since the crisis was such that he was concerned that the cost of union membership may become an expense that workers could ill afford. This has serious implications for the resources of the organisation; he also added that his work in communities had revealed to him the precarious existence many of his members were experiencing:

None of us are free from that absolute poverty...in a couple of months you can be in that absolute poverty no problem, and there seems to be no bounce back from that poverty; that's the scary thing about the crash for me...it's a one-way street, there seems to be no return. One of the saddest things we've had within the trade union community is the amount of suicides because there isn't that hope. (Unemp7 08/2016) 


\section{The Organisational Expression of Solidarity: Missions, Target Groups, Innovation and Key Individuals}

The activities of the TSOs we interviewed ranged along a spectrum: from one end, there was a strong focus on service delivery such as language classes for migrants or services designed for disabled people with specific conditions, to the other end of the spectrum with some organisations such as trade unions emphasising self-organisation in workplaces whilst other TSOs pursued advocacy for all disabled people. There were also a few TSOs which viewed themselves as intermediaries between organisations in their field. Across a broad range of these organisations, there was a consistent theme of having to do more work with fewer resources. Nevertheless, these same organisations were meeting needs in new ways and drawing on their depth of experience to do so, often with scarce resources.

During the course of our interviews with TSOs in the field of migration, it emerged that there seemed to be two different paths which these organisations took: on the one hand, a focus on campaigning, lobbying and mobilising other organisations to support migrants and refugees; on the other hand, organisations which were involved in delivering services directly to migrants and refugees. These latter migration organisations provided services across a broad range of areas including English language classes, counselling, health clinics and assistance with accessing state support as well as more general 'life skills' to help people to adjust to living in the UK. One theme that emerged during the course of our interviews was the importance of voluntarism for some organisations and the complementary role volunteers played alongside paid staff. Furthermore, in terms of those we interviewed, there was a mix between those who had worked in some previous capacity in the field of migration and had brought their experience to bear in their current role, as well as some interviewees who were involved in similar practices but had also been migrants themselves.

In its broadest sense, the target groups for the types of TSOs we interviewed in this field were primarily refugees, asylum seekers and migrants, 
although the activities of these organisations were in some cases focused on meeting particular groups in need. For example, the role of one network which we interviewed in Scotland was to mobilise collaborative efforts between other TSOs to provide assistance to those asylum seekers who were experiencing extreme poverty and destitution. One example of the specific focus of the TSOs was an organisation in the south-east of England which was dedicated to supporting women from migrant communities, assisting them in accessing employment and education, as well as preventing abuse such as domestic violence. Another interviewee explained that, although their organisation had originally begun with a focus on a specific migrant community, it was now offering support to all refugees and asylum seekers. Therefore, despite the clear and consistent emphasis from our interviewees that the focus of their TSOs had been refugees, asylum seekers or migrants, when we drilled down into the details, we found that these definitions were not equally broad across all cases and were often driven by more specialised needs.

Another aspect we explored in our interviews was the types of innovative activities that TSOs undertook in the field of migration. Here, there were consistent themes which emerged across the majority of our interviews; in particular, there were examples provided by the interviewees that frequently involved the delivery of some form of education or skills training or some degree of participation in cultural activities. Another interviewee said that her organisation's main goal of providing a 'voice' to refugees and migrants is an innovative way to address migration/asylum issues in the public debate where people tend to speak on 'behalf' of migrants and refugees rather than letting them speak directly. Although similar concerns, issues and activities could be found in TSOs operating in other fields, there were organisational differences that underpinned the approaches taken across all of the TSOs we interviewed, as exemplified in the field of disability where a background in the health profession often emerged as a key characteristic of a number of organisations.

In the field of disability, our interviewees occupied key positions in their organisations; being either as executive directors or in managerial positions, they were placed in a suitable position to speak on behalf of the organisation. Our interviews reveal that disability TSOs deploy a high level of specialisation and knowledge capacity: several interviewees have a background 
in health (some with a relevant prior career in the National Health Service (NHS); e.g. one was a hospital director) or social work and have joined the third sector after research or work experience on disability or cognate issues (e.g. care, learning and education, etc.). As one interviewee said:

After having spent so many years in the health area of the public sector, I felt I had accumulated the right skills and network for the third sector. When the opportunity arose, I decided to accept the offer and moved to work in the charity sector. (Disab1 10/2016)

Building on these considerations, we conclude that disability TSOs, given the nature of issues they deal with, require health or social care professionals to operate them, people who in addition to passion and a strong ethical inspiration also possess specific knowledge of disability issues in general as well as on the specific impairment/disability that the organisation may focus, alongside first-hand knowledge of the health and care sectors. In fact, our interviews reveal that the field of disability is one in which TSOs have specialised according to diseases or impairments, whilst a few of them (mainly umbrella groups) adopt an overarching, pan-disability approach.

The target groups of the solidarity action of TSOs in this domain are clearly disabled people and their families, and solidarity is conceived as an intimate component of their action since the services they provide and their advocacy campaigns often involve TSOs deploying a practical form of solidarity, being that of support and advice to people in need. Of course, as in the other fields explored in this chapter, there are some TSOs which adopt more politicised approaches; however, the dichotomy between these and more service-oriented TSOs is perhaps less pronounced due to the consistent concern regarding the inclusive nature of joint campaigns and initiatives.

When asked about the innovative character of their work, some TSOs in the field of disability indicated that their activities are at their most innovative when they provide those services which are of primary importance to disabled people, yet to be provided from other sources, and therefore their innovativeness stems from the capacity of the TSO to assist in meeting unmet needs. Other TSOs considered some of their 
services to be innovative because they contributed towards a better understanding of a specific disability. For example, one interviewee, from an association working on a specific disability, said:

Before our association started advocating about this particular form of disability, people ignored how life was for people diagnosed with it; they did not know what it meant for someone to live with the syndrome. Therefore, parents whose baby was diagnosed had no accurate information on which to take a decision about whether to keep the baby or not. Our work has allowed prospective parents to take a decision on the basis of accurate, precise information. Now they can speak with families who have babies with the syndrome and discuss with us about it. (Disab5 10/2016)

Another TSO, based in England, mentioned the tailored services they developed to foster the employability of disabled people, working not only with disabled people themselves but also with employers who are still reluctant, according to these charities, to employ a disabled person. This underlines the barriers to employment faced by disabled people in the UK, and more broadly, labour market challenges have been experienced across communities where TSOs have been operating.

The interviews we conducted with TSOs in the field of unemployment have encompassed a mixed sample of organisational types ranging from trade unions to social enterprises and charities. As with the other themes in our interviews, these TSOs are spread across the UK and have varied remits across international, national and local levels; indeed the challenges and opportunities which emerge from the processes of devolution in the UK quite clearly emerge in some of these interviews.

A clear distinction which also emerged among our interviewees in the unemployment field was that between those organisations which were overtly political, both in terms of how they perceived the economic crisis and in terms of the affiliation of their organisation, and those which were less politicised but still engaging in the policymaking process. Another distinction was the relationship between the organisations and the beneficiaries with some (particularly those in the third sector) having a servicedelivery type relationship with the unemployed/precarious workers (for instance, helping to develop the employability of unemployed people, 
help with CVs and skills development) and the low paid, whereas others (particularly those in the trade unions) were keen to emphasise the importance of self-organisation (such as more activist driven and direct campaigning against low pay, precarity and welfare cuts). It should be noted that there were clear differences in terms of the resources available to each organisation as some key informants were from the largest trade unions in the UK whilst others were from organisations (particularly in the third sector) with only a handful of staff.

The target groups for these organisations are quite varied, ranging from those who are currently employed in various sectors (including retail, creative industries, energy, public sector) to those who are low paid and precariously employed with little occupational identity, as well as young people who were not in employment, education or training. Furthermore, it became clear that both through changing needs, as well as to ensure the ongoing sustainability of the organisation in times of crisis and austerity many had diversified their target groups to include hard-to-reach communities, migrants and refugees.

There were a variety of responses from the interviewees when asked about the innovative activities of their organisations. One theme which emerged across some unemployment organisations concerned the efforts they were making to improve the skills of members and/or service users including training academies to develop the next generation of trade union officials, skills initiatives for young offenders recently released from prison, as well as professional internship programmes with corporations for refugees. One interviewee added that her organisation, which focused on international solidarity with women workers in developing countries, had actively recruited new trustees with a view towards bringing more innovative ideas to the organisation. Another interviewee explained that his social enterprise, based in Wales, which offered support primarily to young unemployed people, had developed a social enterprise start-up initiative which was now being developed into a mobile app. This emphasis on 'reaching out' was encapsulated somewhat by one interviewee from a major trade union, who explained:

An ethos of the union is that we should look beyond our borders...we need to be outward looking. (Unemp10 11/2016) 


\section{The Challenges and Opportunities of Cooperation: Finding Allies at the Transnational, National and Local Levels}

In terms of cooperation with other organisations within and beyond the borders of the UK, our interviews revealed some variation across the three fields. The networks and platforms which TSOs engaged with often reflected not only the size and shape of the organisation but also the scale at which they conducted their main activities. Thus, a number of migrant organisations were well connected locally; disabled people's organisations were often linked to UK-level networks and some European platforms, whereas trade unions were connected through their common affiliation to the Trade Union Congress and European trade union federations. There were, of course, some variations within each field (for instance, some employment-focused social enterprises were better connected locally; some refugee organisations were part of a national network).

\section{The Transnational Level of Cooperation}

In terms of transnational activities and partnerships, we found through the course of our interviews that the migration TSOs appeared to run along a spectrum of some who were quite involved at the transnational level to others who were barely involved in transnational collaborations. One organisation, run by migrants and dedicated to facilitating the greater participation of migrants in British society, was clearly quite well connected at the transnational level, holding memberships of different EU-level platforms and having members actively involved in the running of these platforms. Another interviewee explained that his organisation in Wales was actively developing a collaboration with an Italian refugee organisation whilst another interviewee commented that because of the work their TSO had done in Calais, it had been both useful and necessary to link up with pro-refugee organisations in France. The interviewee added that transnational solidarity was crucial to meeting the needs of refugees: 
It needs to be coordinated throughout the EU rather than country by country, individually and fragmented. We are all appalled with the result of the [Brexit] referendum. This is a worldwide problem; it is not an individual local problem. (Migr1 10/2016)

One important catalyst for some organisations to collaborate with partners in Europe had been through EU-funded projects, although even here there was some variation in the responses with some interviewees from migration TSOs describing EU funding as 'crucial', whereas another interviewee from an organisation focused on a specific migrant community explained that although they had EU funding previously, it had not been pursued for some years. Moreover, one interviewee from an English refugee organisation articulated some scepticism about the amount of resources that could be expended on what could easily be an unsuccessful bid for EU funding, and this chimed to some extent with those interviewees whose organisations were not very engaged at all at the transnational level: a wish to pursue such collaborations but the obligation to concentrate resources elsewhere. As one interviewee explained:

We regard those things as... not as a waste of time, but you can put a lot of time and energy into them and they are not necessarily very successful. (Migr2 10/2016)

These same arguments also emerged in discussions surrounding the membership of migration TSOs of EU-wide umbrellas and networks. However, although there were some overlaps, our interviewees with TSOs engaged in other fields in the UK, raising different types of challenges. When asked about the benefits of such cooperation, all TSOs in the field of disability mentioned the possibility of exchanging experiences and practices (although some of the TSOs commented that they had provided more good practices than they had received, due to the high degree of professionalisation and development in the UK compared to other EU countries). These same organisations also reiterated the importance of being part of larger discussions and awareness-raising campaigns in order for disability issues to be ingrained into transnational or global processes, the effects of which can then reverberate back to the national context (Keck and Sikkink 1998). Others pointed to the beneficial effects of 
transnational cooperation to strengthen fundraising capacities, but also to assist in mobilising volunteers and retaining their existing membership.

When asked about the challenges of such transnational collaborations, the majority of disability TSOs pointed to the diversity of contexts across Europe as posing a problem to long-term collaboration and proper exchange (different health and social care systems and different clinical traditions sometimes obstruct the sharing of best practices and policies). Others mentioned linguistic barriers among the challenging issues of transnational collaboration (here one could speculate that linguistic and cultural homogeneity has facilitated easier links between UK disability charities and North American organisations and umbrella groups, which were reported as key international contacts by some of the interviewees). Finally, a few interviewees, echoing their counterparts in the field of migration, reported the costs of participation in EU projects in terms of the bureaucratic burden, which was considered too high a price for smaller charities. These advantages and disadvantages of transnational cooperation identified by TSOs in the fields of disability and migration were reflected in our interviews in the field of unemployment.

The experience of being involved in transnational partnerships was something that emerged across all of the TSOs we interviewed in the field of unemployment and there were mixed feelings towards these experiences. There was an awareness of the benefits of sharing experience and knowledge with contemporaries in other countries contrasted with concerns about the resources available to sustain these types of links. One social enterprise involved in supporting the unemployed through finding work in the independent media sector was operating across various countries through the work of their member organisations as well as being actively involved with a European Federation. One area where unemployment TSOs (particularly those which were third-sector and social enterprise organisations) had collaborated transnationally was through EU-funded projects; however, there were some who indicated this had been problematic at times. One interviewee explained that she had found the administrative burden of EU funding particularly difficult as her organisation was too poorly resourced to get involved in such projects. Another interviewee explained that although her organisation based in Manchester was actively involved in other countries (particularly in 
Africa), it had in recent years become more cautious about developing links with, for example, some trade unions there as there were issues surrounding splits and rivalries that her organisation was keen to avoid.

Each of the trade unions we spoke to were members of various European trade union federations in both public and private sectors. One interviewee, a London-based national officer in a public sector trade union, explained that he had frequent contact with colleagues in Europe and recounted a recent visit where he had discussed the impact of austerity with public sector workers in both Spain and Greece which he described as a learning experience. Another officer from a large UK trade union, who was based in Glasgow, explained that he had recently been involved in working and sharing information with colleagues in the USA and that his union had been particularly active at a more global level. Across the trade unions the idea that acting in concert with international partners was seen as particularly beneficial for lobbying efforts with one official explaining the importance of this in opposing the Transatlantic Trade and Investment Partnership (TTIP). Nevertheless, one official from a trade union indicated that there was pressure from his membership to concentrate resources on the UK context where there was a constant threat of job losses rather than international work. The official explained that any failure to be responsive to concerns of the membership could mean people may 'vote with their feet' and that although they have continued to maintain links with sector-specific federations in Europe, in more general terms the transnational work in the past few years has fallen down the list of priorities for the impact of the crisis was refocusing the TSO towards more local concerns:

We have tended to contract that...our members view is we need to protect ourselves before everyone else. (Disab2 10/2016)

\section{The Local and National Level of Cooperation}

One aspect we explored in our interviews in the field of migration concerned the various types of partnerships and collaborations that the TSOs had developed in order to better meet the needs of the refugees, asylum 
seekers and migrants whom they were supporting. Despite the clear variations, perhaps due to the geographical location or the high degree of informality which characterised some of the groups we spoke to, there was a clear theme emerging that many were very well connected at the local level. Indeed, some of the migration organisations in the sample had been specifically set up with the purpose of mobilising local people and organisations to ensure that refugees would be welcomed when they arrived in their town. Other organisations, such as one we interviewed in central Scotland, specifically acts as an intermediary between different types of groups in order to provide support to some of the very poorest refugees in inner cities. Another interviewee explained that her organisation, based in the south-east of England, had developed a good working relationship with a local university and were also members of voluntary umbrella organisations. Therefore, it was often the local context which shaped the landscape for partnerships for many of the TSOs we spoke to, and this was evident even when these organisations were sometimes linked in some way with a UK-level organisation. There was one organisation with branches across three major UK cities which was specifically aimed at developing lobbying activities for migrants, refugees and asylum seekers, yet despite being geographically spread across the UK still maintained the importance of local-level partnerships. Therefore, perhaps to a certain extent, the field of migration in the UK appears to be populated by organisations which focus their day-to-day activities on more local levels even when the TSOs themselves were part of broader, national movements, although it was clear that the national-level networks were an important focal point for information sharing.

As with some migration TSOs, most of the TSOs in the disability field are connected either to a UK-based network or to an international one. When asked about the reasons for being connected to other charities or organisations, all of the TSOs in this field emphasised the possibility of having their voices heard more effectively. This seems to be particularly relevant for those charities focusing on disabilities originating from rare diseases or those who work on mental health issues, which have come to be considered, during a time of economic recession and public sector cuts, as less relevant than physical impairments according to the findings emerging from our interviews. As one interviewee told us: 
For charities working on rare diseases, it is essential to be part of umbrellas and network organisations, as that is the way we can have our voice heard. (Disab1 10/2016)

Therefore, only through connecting with and joining with other organisations will disability TSOs have opportunities to be heard by policymakers and the media. For some of these 'niche-focused' TSOs, it is also a matter of resources and costs: they simply do not have the human resources or economic resources available, for example, to attend multiple policy discussion fora or policymaking arenas, and therefore they rely on their umbrella organisation to undertake this work for them. The advantages of being part of a broader alliance were also identified by TSOs operating in other fields in the UK. For example, all of the TSOs we spoke to in the field of unemployment were linked in some way to a wider body or platform, and this was variable across different scales with some third-sector organisations, in particular, being much more linked in to those bodies which were operating in their local contexts. This was by no means reflective of all third-sector organisations since others-such as one particular charity-operated across the UK and had built relationships across different areas and with various local authorities and community planning partnerships. One interviewee, a director of a social enterprise, explained that developing partnerships with others had become a key issue in Wales, where they were based, since there were now so many organisations operating in this field that there needed to be a much more coherent strategy to ensure these different groups collaborated more effectively.

Perhaps unsurprisingly, the trade unions we spoke to were well connected to unions that operated in similar fields (e.g. public or private sector), and either the interviewees themselves or their colleagues were actively involved in the work of platforms such as the Trade Union Congress. One interviewee, who is an officer in a trade union where the UK-wide membership is drawn mainly from the private sector, explained that she now viewed it as her role to build partnerships with organisations that were normally outside of the comfort zone of her trade union, such as small business employers (where workers were often non-unionised) or 
religious organisations in order that the trade union can be more effective in its campaigning.

Therefore, cooperation and partnership were not only perceived as beneficial but in some cases crucial to the effectiveness of the organisation in performing its mission and meeting the needs of the groups in society with whom they organised to support at both local and national levels.

\section{Conclusions: Main Findings and Implications}

In this chapter, we have sought to answer the question of how transnational solidarity organisations can meet the needs of vulnerable groups in times of crisis and austerity. In doing so, we discovered a tale of two Britains: one which constructs a hostile and punitive policy environment for vulnerable groups and another which expresses its solidarity with these same groups through organisations by meeting their needs and advocating for change. The TSOs we interviewed are not exhaustive of the efforts taking place in UK society to express solidarity, but our sample offers an insight into the experiences of key actors at a critical juncture in UK society. The TSOs we interviewed have come under increasing strain in a context of austerity where they are often expected to do more with fewer resources and under such pressure, the capacity to pursue transnational linkages has become depleted as organisations try to meet the growing needs of vulnerable groups within the UK.

A core strength of the organisations we interviewed is the people who form them, who connect others in a mission of solidarity both within and beyond the borders of the UK and whose expertise (Osborne et al. 2008) is built upon decades of experience, thus deploying a high degree of competence and knowledge to advocate for better protection and living conditions. This often manifested itself in meeting specialised needs (such as pioneering efforts by disability TSOs to raise awareness of the impact of particular conditions), or a focus on groups in society who were more likely to fall between the cracks of statutory service provision. Such organisations are the very core of the solidarity this book seeks to understand as they work to provide much-needed services which would not be available otherwise and to raise awareness among citizens about the challenges faced by groups as diverse as the unemployed, the disabled and refugees. 
Despite performing this critical role, these organisations have themselves come under intense pressure as they attempt to sustain their work amidst an increasingly difficult funding environment in which their already stretched capacities come under even greater strain. This insight has led us to a more nuanced conclusion regarding the relationship between TSOs and policymakers at different levels: on the one hand, central government with the top-down discourses which emanate from it is often perceived as an obstacle which these organisations and their beneficiaries must overcome and, on the other hand, local government, where a more active and partnership-based relationship becomes evident, perhaps built on a shared experience of the impact of austerity at the local level. Somewhat worryingly, it seems that for some organisations, the focus on sustaining their operations in their own local contexts in the UK has in some cases come at the cost of sustaining or exploring greater collaboration across borders at a time when European solidarity is under pressure from populist and reactionary forces. Therefore, our findings should act as a warning sign for those who value solidarity and social cohesion; there are implications for society when TSOs come under everincreasing strain whilst public spending is in retreat: inequalities widen while human needs grow.

What our findings reveal is a need to broaden the scope of investigations into the impact of austerity beyond the local and national contexts and to scrutinise the implications for social cohesion by encompassing the simultaneous impact of austerity on the opportunities and capacities for transnational collaboration and solidarity. It is from the consequences of these findings that a future research agenda, around which the contours of solidarity in post-Brexit Britain, can be shaped.

\section{References}

Bambra, C., \& Smith, K. (2010). No Longer Deserving? Sickness Benefit Reform And the Politics of (Ill) Health. Critical Public Health., 20(1), 71-83. Baumberg, B., Warren, J., Garthwaite, K., \& Bambra, C. (2015). Rethinking the Work Capability Assessment. London: Demos. 
Darlington, R., \& Dobson, J. (2015). The Conservative Government's Proposed Strike Ballot Thresholds: The Challenge to the Trade Unions. Salford Business School Research Working Paper August 2015.

Ferguson, K. (2016, June 26). EU Referendum: Immigrants Told to 'Leave UK Now' After 'Divisive and Xenophobic' Brexit Campaign, Warsi says. The Independent.

Garthwaite, K. (2011). 'The Language of Shirkers and Scroungers?' Talking About Illness, Disability and Coalition Welfare Reform. Disability and Society, 26(3), 369-372.

Greenslade, R. (2005). Seeking Scapegoats: The Coverage of Asylum in the UK Press (Vol. 5). London: Institute for Public Policy Research.

Keck, M. E., \& Sikkink, K. (1998). Activists Beyond Borders: Advocacy Networks in International Politics. Ithaca: Cornell University Press.

O'Hara, M. (2015). Austerity Bites: A Journey to the Sharp End of Cuts in the UK. Bristol: Policy Press.

Osborne, S. P., Chew, C., \& McLaughlin, K. (2008). The once and Future Pioneers? The Innovative Capacity of Voluntary Organisations and the Provision of Public Services: A Longitudinal Approach. Public Management Review, 10(1), 51-70.

Patrick, R. (2014). Working on Welfare: Findings from a Qualitative Longitudinal Study into the Lived Experiences of Welfare Reform in the UK. Journal of Society Politics, 43(04), 705-725.

Peck, J., \& Tickell, N. (2002). Neoliberalising Space. Antipode, 34, 380-404. Pennycook, M., Cory, G., \& Alakeson, V. (2013). A Matter of Time: The rise of Zero-Hours Contracts. London: Resolution Foundation.

Prime Minister's Office. (2013). Immigration Speech by the Prime Minister. Retrieved from: https://www.gov.uk/Government/news/immigration-speechby-the-prime-Minister

Shildrick, T., MacDonald, R., \& Webster, C. (2012). Poverty and Insecurity. Bristol: The Policy Press.

Smulian, M. (2017). LGA: Councils Face £5.8bn Funding Gap by 2020. Retrieved from: Public Finance. http://www.publicfinance.co.uk/news/2017/ 07/lga-councils-face-ps58bn-funding-gap-2020

Statham, P., \& Geddes, A. (2006). Elites and the "Organised Public": Who Drives British Immigration Politics and in Which Direction? West European Politics, 29(2), 248-269. 
Stewart, E., \& Mulvey, G. (2014). Seeking Safety Beyond Refuge: The Impact of Immigration and Citizenship Policy Upon Refugees in the UK. Journal of Ethnic and Migration Studies, 40(7), 1023-1039.

TransSOL. (2016). Work Package 2 Integrated Report on Reflective Forms of Transnational Solidarity. Retrieved from: https://blogs.uni-siegen.de/transsol/files/2016/12/Integrated-Report-on-Reflective-Forms-of-TransnationalSolidarity.pdf

United Nations. (2016). Inquiry Concerning the United Kingdom of Great Britain and Northern Ireland Carried Out by the Committee Under Article 6 of the Optional Protocol to the Convention. Geneva: Committee on the Rights of Persons with Disabilities.

Watts, B., \& Fitzpatrick, S. (2018). Welfare Conditionality. London: Routledge. Wiggan, J. (2012). Telling Stories of 21st Century Welfare: The UK Coalition Government and the Neo-liberal Discourse of Worklessness and Dependency. Critical Social Policy, 32(3), 383-405.

Wright, S. (2012). Welfare-to-Work, Agency and Personal Responsibility. Journal of Social Policy, 41(02), 309-328.

Open Access This chapter is licensed under the terms of the Creative Commons Attribution 4.0 International License (http://creativecommons.org/licenses/ by/4.0/), which permits use, sharing, adaptation, distribution and reproduction in any medium or format, as long as you give appropriate credit to the original author(s) and the source, provide a link to the Creative Commons licence and indicate if changes were made.

The images or other third party material in this chapter are included in the chapter's Creative Commons licence, unless indicated otherwise in a credit line to the material. If material is not included in the chapter's Creative Commons licence and your intended use is not permitted by statutory regulation or exceeds the permitted use, you will need to obtain permission directly from the copyright holder.

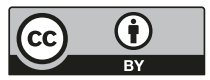

